\title{
(2) OPEN ACCESS \\ Bilateral pleural effusion and pneumomediastinum: rare complication resulting from punctured left subclavian vein following insertion of PICC line for total parenteral nutrition
}

\author{
Saquib Navid Siddiqui $\odot,{ }^{1}$ Muhammad Memon, ${ }^{2}$ Tanveer Hasan ${ }^{2}$
}

${ }^{1}$ Respiratory Medicine \& General Internal Medicine, Northumbria Healthcare NHS Foundation Trust, North Shields, UK ${ }^{2}$ Geriatric Medicine, William Harvey Hospital, Ashford, UK

\section{Correspondence to}

Dr Saquib Navid Siddiqui; sns.saquib@gmail.com

Accepted 24 June 2021

Check for updates

(c) BMJ Publishing Group Limited 2021. Re-use permitted under CC BY-NC. No commercial re-use. See rights and permissions. Published by BMJ.

To cite: Siddiqui SN, Memon M, Hasan T. BMJ Case Rep 2021:14:e244093. doi:10.1136/bcr-2021244093

\section{SUMMARY}

This is a rare case of development of bi-lateral chylous pleural effusion (containing parenteral nutrition material) along with pneumomediastinum due to punctured left subclavian vein following insertion of a peripherally inserted central venous catheter (PICC) line. Parenteral nutrition is usually preferred for patients unable to tolerate enteral feeding. Due to hypertonicity of the total parenteral nutrition material, it is usually administered via internal jugular or subclavian vein which have a rapid blood flow; therefore, resulting in adequate mixing. Literature studies are yet to clearly explain the communications between two pleural cavities; therefore, development of bilateral pleural effusions in association with pneumomediastinum makes this case more intriguing. We present the journey of a 43-year-old woman who required insertion of bilateral chest drains, followed by sternotomy and repair of the left subclavian vein after she was found in hypoxic respiratory failure 2 days following insertion of PICC line into her left subclavian vein.

\section{BACKGROUND}

Central venous catheterisations using portable ultrasound devices have reduced potential complications arising from such procedure. Complications associated with peripherally inserted central venous catheter (PICC) line insertion include vascular erosion, pneumothorax, pleural effusion, thrombophlebitis, brachial plexus injury, mediastinal haematoma, etc. Although ultrasound-guided placement of the central venous catheter significantly nullifies the potential risk associated with it,but may not prevent a vascular perforation or malposition. This case depicts such incidence of perforation of the left subclavian vein by the PICC line, resulting in accumulation of parenteral nutrition material within two pleural cavities associated with concomitant pneumomediastinum.

\section{CASE PRESENTATION}

A 43-year-old woman was admitted under the surgical team with abdominal pain, vomiting and $2 \mathrm{~kg}$ unintentional weight loss in past 3 months. She was diagnosed as a new case of Crohn's disease. CT abdomen-pelvis performed during admission revealed complicated $9 \mathrm{~cm}$ terminal ileal wall thickening with narrow lumen and loculated perforation of the terminal ileum with a small abscess in the right iliac fossa. Thereafter, she underwent a right hemicolectomy, followed by another laparotomy 2 weeks later to perform adhesiolysis and refashioning of the anastomosis as she was found to have terminal ileal adhesion to with the pelvic wall along with a small hole in anastomotic site. She was started on parenteral feeding after the laparotomy as was not able to tolerate enteral feeding. A PICC line was inserted in her left internal jugular vein following which antero-posterior chest X-ray confirmed satisfactory position of the PICC line. She had no respiratory distress for the first couple of days post PICC line insertion. Two days after the commencement of total parenteral nutrition (TPN), she was noted to become breathless. ABG showed hypoxic respiratory with a po2 of 6.9. Initial thought was whether she developed a pulmonary embolism considering recent surgery and immobility despite remaining on prophylactic anticoagulation while stay in the hospital. Immediate CT-pulmonary angiogram was performed which revealed PICC line punctured left subclavian vein with an extra luminal extension of about $2 \mathrm{~cm}$ in the mediastinum leading into bilateral pleural effusion and pneumomediastinum with collapse of both lower lobes (figures 1 and 2). Considering the complexity of the CT findings, it was referred to the medical on call team overnight. After stopping the TPN infusion, medical registrar on call discussed the case with the cardiothoracic surgeon who recommended the immediate transfer of the patient for a possible sternotomy and removal of the PICC line with subclavian vein repair to be performed by the vascular surgeons. Prior to transfer, she would require the insertion of bilateral chest drains to relief her symptoms and also to aid in for any possible haemothorax. Thereafter bilateral $18 \mathrm{~F}$ chest drain tube were inserted by the medical registrar overnight by seldinger method. A $1 \mathrm{~L}$ white, milky fluid was drained from the left-hand side and other similar consistency $1 \mathrm{~L}$ red tinged fluid was drained from right-hand side (figure 3). Both drains were clamped to avoid re-expansion pulmonary oedema considering the volume and rapid drainage of fluid. Pleural fluid sample was sent to the laboratory and post chest drain chest X-ray was performed which showed resolving bilateral pleural effusion (figure 4). She was immediately transferred to the cardiothoracic centre where she underwent a sternotomy and removal of the PICC line with primary repair of the left subclavian vein. 


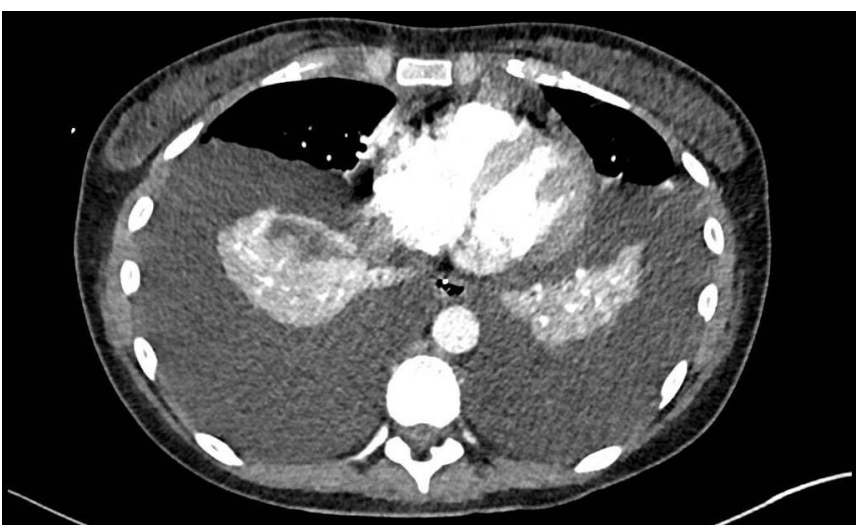

Figure 1 Axial view of CT pulmonary angiogram revealing bilateral pleural effusion and pneumomediastinum with collapse of both lower lobes.

She was later treated with antibiotics, daily pleural drainage and parenteral nutrition through a PICC line inserted in her right internal jugular vein, which was later removed without any further complications once she was able to tolerate enteral feeding. The two pleural fluid sample was consistent with TPN contamination: visibly lipaemia (left more than right as right pleural fluid was red tinged colour) with triglycerides of 4.40 $\mathrm{mMol} / \mathrm{L}$ and $4.70 \mathrm{mMol} / \mathrm{L}$.

\section{OUTCOME AND FOLLOW-UP}

Rapid and simultaneous action plan from the medical and surgical team helped to save the patient from imminent life endangering situation while later required long hospital stay for daily chest drainage, antibiotics and nutritional support.

\section{DISCUSSION}

PICC placement remains to be the most common vascular interventional procedure performed throughout the world. As the name suggests the procedure involves inserting the catheter in a peripheral vein and advanced to such extent that only its tip lies in the central venous system. Common indications of administrating a PICC are TPN and infusion of medications for long duration (14 days or greater but less than 3 months). ${ }^{1}$ Preliminary safety checklist prior to insertion of PICC includes optimisation of coagulation profile to nullify the risk of bleeding. International normalised ratio (INR) should be $<2.0$, INR above 2.0 will require treatment with Fresh Frozen Plasma or vitamin K. Minimal platelet count required is $20 \times 10^{9} / \mathrm{L}$, with blood transfusion recommended for counts below $20 \times 10^{9} / \mathrm{L}$. Clopidogrel should be withheld for 5 days prior to the procedure, whereas

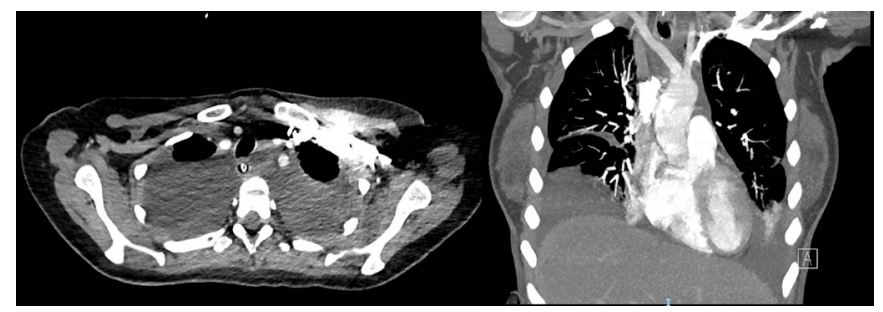

Figure 2 CT pulmonary angiogram showing PICC line punctured left subclavian vein with an extra luminal extension of about $2 \mathrm{~cm}$ in the mediastinum leading into bilateral pleural effusion and pneumomediastinum with collapse of both lower lobes. PICC, peripherally inserted central venous catheter.

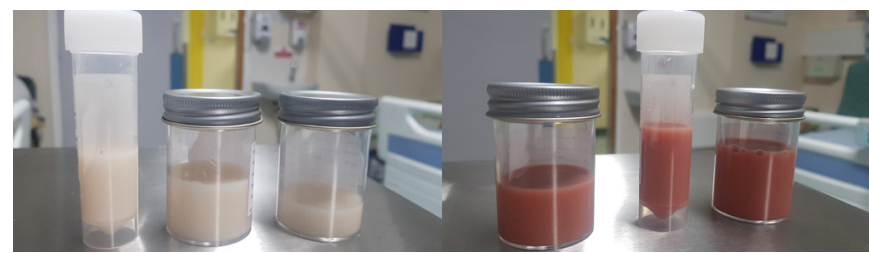

Figure 3 Milky white fluid drained from left pleural cavity whereas red tinged similar consistency pleural fluid drained from right pleural cavity.

it is safe to withhold one therapeutic dose of low-molecularweight heparin before the procedure. There is no need to withhold aspirin for PICCs. ${ }^{2}$ Immediate complications related to PICCs include vascular, cardiac, pulmonary and placement complications, whereas delayed complications, mostly include device dysfunction (fibrin sheath sheath formation, fracture, thrombosis, central venous stenosis) and infection. Vascular injuries are greatly influenced by the use of ultrasound and operator experience. The incidence of vascular perforation by Central venous catheter/PICC line for TPN, although is reported to be very low $(0.17 \%)$ but remains a serious threat to the patient's life as the mortality rate is high. ${ }^{3}$ Ultrasound guidance administration of PICC has shown to lower the risk of complications of all access sites. ${ }^{45}$ Pulmonary complications include pneumothorax, pneumomediastinum, chylothorax, tracheal injury, injury to recurrent laryngeal nerve and air embolism. Pneumothorax and pneumomediastinum occurs approximately in 1\% cases and are mostly related to subclavian catheter placement. ${ }^{6-8}$ Risk factors for pneumothorax are the larger catheter size and number of attempted insertions. If the size of the pneumothorax is less than $<15 \%$, it can be managed conservatively with high flow oxygen, but hypoxia and haemodynamic instability obviate the need for emergency chest drain which happened in our case. Possible explanations for developing chylothorax are an accumulation of TPN material into the pleural cavities resulting from a punctured subclavian vein, venous ingestion or injury to the lymphatic. Left internal jugular vein or subclavian vein access carries higher risk of lymphatic injury due to the anatomical location of the thoracic duct. Cardiac complications feature risk of developing arrhythmia and cardiac arrest. In general, internal jugular vein catheterisation is a safe procedure; despite a low

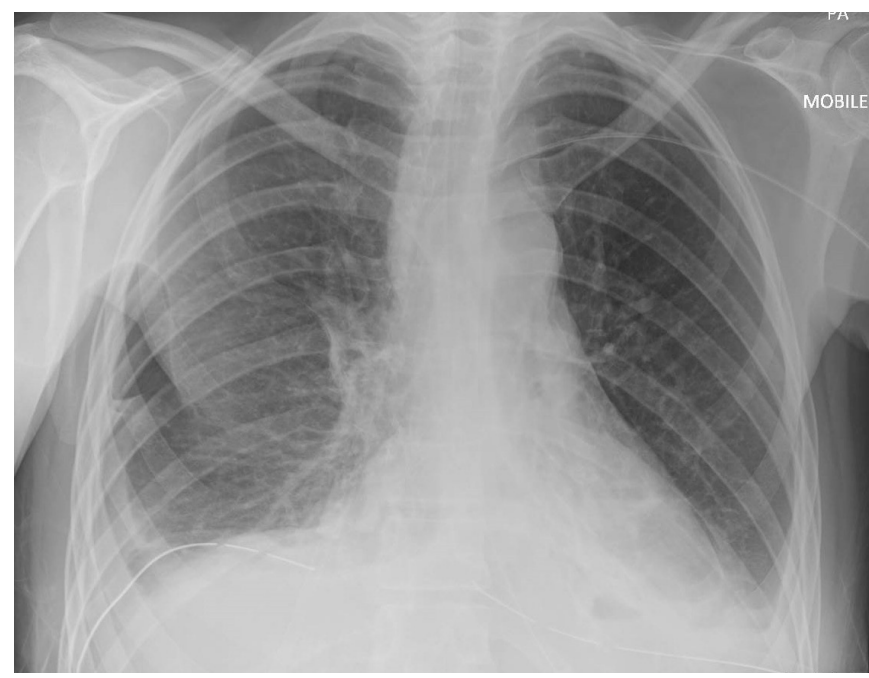

Figure 4 Post chest drain chest X-ray was performed which showed resolving bilateral pleural effusion. 
number of incidences of vascular malposition or puncture being reported following internal jugular vein PICC line inserted, the majority has been reported with left internal jugular vein. A possible explanation is right internal jugular vein runs a fairly straight course into the right brachiocephalic vein whereas left internal jugular vein forms a greater bend while forming the left brachiocephalic vein.

This is a case of bilateral pleural effusions with pneumomediastinum due to punctured left subclavian vein after attempted left internal jugular venous cannulation. We have reports of ipsilateral pleural effusion following misplaced central venous catheters. ${ }^{90}$ There are a couple of rare cases being reported to have bilateral pleural effusion, but none had associated pneumomediastinum and a punctured subclavian vein. ${ }^{11}{ }^{12}$ Although likely communications between pleural and peritoneal cavities have been reported before, but little information exists in the literature about channels communicating between the two pleural cavities. ${ }^{13}$ This makes the case more unusual. A likely explanation for the fluid passage into both pleural cavities is migration of the tip of the PICC line into the mediastinum following puncturing the left subclavian vein; therefore, fluid could pass into both pleural cavities via anatomical communications existing between the two pleural cavities. Looking at the case retrospectively reveals sadly TPN material was being feed into her two pleural cavities for 2 days which led into development of bilateral pleural effusion and then compressing both lungs resulting in bilateral pulmonary collapse. Potential injury to the lung parenchyma by the tip of the PICC line resulted in further development of a pneumomediastinum. All the factors contributed leading her into hypoxic respiratory failure. Rapid identification

\section{Learning points}

- Hypoxic respiratory failure postperipherally inserted central venous catheter (PICC) line insertion may be due to development of pleural effusion or pneumothorax resulting from complications associated with insertion of the PICC line warranting immediate chest X-ray.

- Monitoring of the PICC line daily with ultrasound surveillance may prevent developing such catastrophic conditions.

- In case of pleural effusion/pneumomediastinum resulting from vascular perforation caused.

- By PICC line will require immediate multidisciplinary action to save the life of the patient.

- Rapid insertion of bilateral chest drains followed by removal of the PICC line and repair of the left subclavian vein after a sternotomy was life-saving in our case. and insertion of the two chest drains followed by immediate transfer and surgical repair saved the life of the patient from a high mortality life-threatening situation.

Twitter Saquib Navid Siddiqui @Saquib Navid

Contributors SNS: lead and corresponding author. MM and TH: coauthor.

Funding The authors have not declared a specific grant for this research from any funding agency in the public, commercial or not-for-profit sectors.

Competing interests None declared.

Patient consent for publication Obtained.

Provenance and peer review Not commissioned; externally peer reviewed.

Open access This is an open access article distributed in accordance with the Creative Commons Attribution Non Commercial (CC BY-NC 4.0) license, which permits others to distribute, remix, adapt, build upon this work non-commercially, and license their derivative works on different terms, provided the original work is properly cited and the use is non-commercial. See: http://creativecommons.org/ licenses/by-nc/4.0/.

\section{ORCID iD}

Saquib Navid Siddiqui http://orcid.org/0000-0003-4308-7030

\section{REFERENCES}

1 Chopra V, Flanders SA, Saint S, et al. The Michigan appropriateness guide for intravenous catheters (magic): results from a Multispecialty panel using the RAND/ UCLA appropriateness method. Ann Intern Med 2015;163:S1.

2 Gupta N, Gandhi D, Sharma S. Tunneled and routine peripherally inserted central catheters placement in adult and paediatric population: review, technical feasibility, and troubleshooting. Quant Imag Med Sur 2020. doi:10.21037/qims-20-694

3 Walshe C, Phelan D, Bourke J, et al. Vascular erosion by central venous catheters used for total parenteral nutrition. Intensive Care Med 2007;33:534-7.

4 Powell JT, Mink JT, Nomura JT. Ultrasound-guidance can reduce adverse events during femoral central venous cannulation. J Emerg Med 2014:46:519-24.

5 Leung J, Duffy M, Finckh A. Real-time ultrasonographically-guided internal jugular vein catheterization in the emergency department increases success rates and reduces complications: a randomized, prospective study. Ann Emerg Med 2006;48:540-7. doi:10.1016/j.annemergmed.2006.01.011

6 McGee DC, Gould MK. Preventing complications of central venous catheterization. N Engl J Med 2003;348:1123-33.

7 Bhutta ST, Culp WC. Evaluation and management of central venous access complications. Tech Vasc Interv Radiol 2011;14:217-24.

8 Vats HS. Complications of catheters: tunneled and nontunneled. Adv Chronic Kidney Dis 2012;19:188-94.

9 Rudge $\mathrm{CJ}$, Bewick M, McColl I. Hydrothorax after central venous catheterization. $\mathrm{Br}$ Med J 1973;3:23-5.

10 Thomas CJ, Butler CS. Delayed pneumothorax and hydrothorax with central venous catheter migration. Anaesthesia 1999;54:987-90.

11 Campagnutta E, Segatto A, Maesano A, et al. [Bilateral hydrothorax with hydromediastinum after cannulation of the left internal jugular vein]. Minerva Ginecol 1989;41:479-83

12 Simmons TC, Henderson DR. Bilateral pleural and pericardial effusions because of mediastinal placement of a central venous catheter. JPEN J Parenter Enteral Nutr 1991:15:676-9.

13 Kanno T, Yoshikawa D, Tomioka A, et al. Hydrothorax: an unexpected complication after laparoscopic myomectomy. Br J Anaesth 2001;87:507-9.

Copyright 2021 BMJ Publishing Group. All rights reserved. For permission to reuse any of this content visit

https://www.bmj.com/company/products-services/rights-and-licensing/permissions/

BMJ Case Report Fellows may re-use this article for personal use and teaching without any further permission.

Become a Fellow of BMJ Case Reports today and you can:

- Submit as many cases as you like

- Enjoy fast sympathetic peer review and rapid publication of accepted articles

- Access all the published articles

- Re-use any of the published material for personal use and teaching without further permission

Customer Service

If you have any further queries about your subscription, please contact our customer services team on +44 (0) 2071111105 or via email at support@bmj.com.

Visit casereports.bmj.com for more articles like this and to become a Fellow 